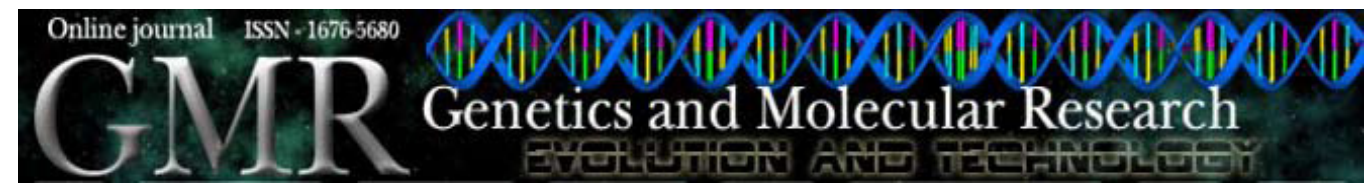

\title{
Differential gene expression patterns in the autogamous plant Hordeum euclaston (Poaceae)
}

\author{
J.E. Georg-Kraemer ${ }^{1,3}$, C.A.S. Ferreira ${ }^{2,3}$ and S.S. Cavalli ${ }^{3}$ \\ ${ }^{1}$ Laboratório da Biodiversidade Vegetal, \\ Programa de Pós-Graduação em Genética e Toxicologia Aplicada, \\ Universidade Luterana do Brasil, Canoas, RS, Brasil \\ ${ }^{2}$ Departamento de Biologia Celular e Molecular, Faculdade de Biociências, \\ Pontifícia Universidade Católica, Porto Alegre, RS, Brasil \\ ${ }^{3}$ Departamento de Genética, Universidade Federal do Rio Grande do Sul, \\ Porto Alegre, RS, Brasil
}

Corresponding author: J.E. Georg-Kraemer

E-mail: janaina.kraemer@terra.com.br

Genet. Mol. Res. 10 (1): 295-310 (2011)

Received September 20, 2010

Accepted November 22, 2010

Published February 22, 2011

DOI 10.4238/vol10-1gmr1017

\begin{abstract}
Sib-seedlings of 95 strains of the strictly autogamous grass Hordeum euclaston were analyzed by horizontal polyacrylamide gel electrophoresis for four isoenzyme systems at a specific ontogenetic stage. We found differences in the activity of some genes among individuals of this species. Hence, an ontogenetic analysis was carried out to investigate 12 strains at five ontogenetic stages, to determine the patterns of expression of these genes during development. The differences in the presence versus absence of certain isoenzyme bands may be due to differential regulatory activation in response to environmental differences, as all plants showed the same structural genes, although these genes were active in different tissues and/or times of development. These results indicate the importance of differential gene activation in the metabolic phenotype variability of this strictly autogamous, highly homozygous species. The same structural alleles for isoenzymes showed
\end{abstract}


the active form of the enzymes (phenotypic expression) to be present in different tissues and/or stages of development. Differential isoenzyme gene activation was shown to be directly responsible for the enzymatic variability (metabolic phenotype) presented by the plants, which seem to possess almost no heterozygosis.

Key words: Gene expression; Ontogenetic stages; Genetic variability; Isoenzymes

\section{INTRODUCTION}

In several grasses, growth is characterized by an orderly sequence of ontogenetic events (development), such as coleoptile emergence, floral initiation and anthesis. These events trigger the coordinated initiation, appearance and growth of tissue structures (such as leaves, stems, spikes, and grain), characteristics of the mature plant (Jalal Kamali and Boyd, 1999). This sequence of events is determined primarily by regulatory genes, which are able to guide the development of individuals by determining the formation of differentiated cells of all tissues and organs from a single fertilized cell. Indeed, the process is accomplished through a specific and ordered regulatory program of cell genome expression, which leads to the final phenotype of the individual (Grotewold, 2005).

Nowadays, the influence of environmental conditions on development is one of the objects of interest in ontogenetic studies. Continuous organogenesis makes plant development extraordinarily flexible at all levels (Walbot, 1996), and as reviewed by Sultan (2005), studies of plant plasticity have revealed not only immediate morphological and allocational responses to environmental factors, but also complex environmental effects on ontogenetic trajectories (Weinig and Delph, 2001) and offspring traits (Lundgren and Sultan, 2005).

Although microarray analyses are the most modern and robust tools for studies on gene expression patterns, isoenzymes have also been used as probes to investigate the regulation of gene expression during the development of an organism as well as the differentiation of an organ or tissue at a given ontogenetic stage. This is because isoenzymes represent the end-product of a specific gene function, and therefore, they reflect the differentiated state of a cell, organ or tissue. Consequently, differences in regulatory patterns result in the alteration of enzyme synthesis, activity level, and/or site and time of expression. Variations in gene expression are known to play an important role in the evolutionary process of adaptive divergence among natural populations (Larsen et al., 2007).

Isoenzymes have also been widely and successfully used as markers to study the genetic variability of natural populations of a large number of species. Nevertheless, these studies have only considered structural gene polymorphisms without taking into account regulatory differences. This probably occurs because, until recently, it was unclear whether regulatory genes present genetic variation within species to serve as material for evolutionary diversification. Studies have pointed out the high heritability of gene regulation (Whitehead and Crawford, 2006). The dramatic effect of mutants of many regulatory genes suggested that these genes would be under strong stabilizing selection and thus would possess little variation. More recently, several authors have proposed that changes in a small number of regulatory genes may be sufficient for the evolution of novel morphologies (Bramley, 2002; Koes et al., 2005). 
However, the present knowledge of the evolutionary forces that guide the diversification of regulatory genes is still extremely limited.

In this paper, we proposed the contribution of differential regulatory activation to increase phenotypic variability in a wild barley species - Hordeum euclaston. This species is herbaceous, annual, diploid $(2 \mathrm{n}=14)$, and widely distributed in Southern Brazil, Uruguay and Argentina (von Bothmer et al., 1982). H. euclaston produces a floral structure with small anthers, which are not excluded from the florets, suggesting the occurrence of cleistogamy. The reproduction system was investigated by Ferreira and Cavalli-Molina (1994), who showed no allelic variation in structural genes in the analyses of sib-seedlings from several progenies, i.e., all sib-seedlings were homozygous for the same allele for the 26 isoenzyme genes studied when the same tissue and the same ontogenetic stage were analyzed. These results clearly indicate the absence of gene segregation and confirm that $H$. euclaston is an autogamous species. This condition of $\mathrm{H}$. euclaston is particularly interesting for this study because plants from the same strain (progeny from a single plant) share the same gene pool, and different sib-plants can be analyzed in different developmental stages, representing the same genotype.

Therefore, the goal of this study was to analyze the contribution of regulatory differences among individuals of $H$. euclaston and to discuss their mechanisms and consequences for the physiologic variability of this species.

\section{MATERIAL AND METHODS}

\section{Experiment 1}

Seeds of 95 plants of $H$. euclaston were collected from three populations from the western region of Rio Grande do Sul State, Southern Brazil (Table 1). These populations were the same studied by Ferreira and Cavalli-Molina (1994).

Table 1. Strains of the three populations analyzed in Experiment 1 and collection sites.

\begin{tabular}{|c|c|c|}
\hline Population & Site (country) & Strains \\
\hline 1 & $\begin{array}{l}\text { Alegrete, RS, BR; on BR } 290 \text { highway } \\
\text { (Porto Alegre - Uruguaiana city), } 13 \mathrm{~km} \\
\text { from Alegrete city; } 30 \text { plants }\end{array}$ & $\begin{array}{l}\text { HW3078; HW3080 to 83; HW3086 to 89; HW3152; HW3154; HW3156; } \\
\text { HW3158 to 60; HW3162 to 65; SCM1017; SCM1019; SCM1021; SCM1023; } \\
\text { SCM1026; SCM1028 to 29; SCM1031 to 32; SCM1034; SCM1037 }\end{array}$ \\
\hline 2 & $\begin{array}{l}\text { Alegrete, RS, BR; on an unpaved road, } \\
44 \mathrm{~km} \text { from site } 1 ; 32 \text { plants }\end{array}$ & $\begin{array}{l}\text { HW3095; HW3099; HW3101 to 02; HW3104 to 05; HW3171 to } 77 \text {; HW3179 to 80; } \\
\text { HW3182 to 83; HW3188; HW3190 to 91; HW3193; SCM1038; SCM1040; } \\
\text { SCM1042 to 43; SCM1045; SCM1048; SCM1050 to 53; SCM1055 }\end{array}$ \\
\hline 3 & $\begin{array}{l}\text { Quaraí, RS, BR; on BR } 377,39 \mathrm{~km} \\
\text { from Quaraí city, } 96 \mathrm{~km} \text { from site } \\
2 ; 33 \text { plants }\end{array}$ & $\begin{array}{l}\text { HW3121; HW3128; HW3130; HW3132 to 34; HW3136; HW3139; HW3238; } \\
\text { HW3240; HW3244; HW3246; HW3249; HW3253; HW3256; HW3258 to 59; } \\
\text { HW3282; HW3297 to 98; SCM1104 to 05; SCM1107; SCM1111 to 13; SCM1115; } \\
\text { SCM1119; SCM1122; SCM1125 to 26; EKS3B; EKS3H }\end{array}$ \\
\hline
\end{tabular}

$\mathrm{RS}=$ State of Rio Grande do Sul; BR = Brazil. Collectors: HW = Helga Winge; $\mathrm{SCM}=$ Suzana Cavalli Molina; EKS $=$ Eliane Kaltchuk Santos.

Seeds were germinated on wet filter paper on Petri dishes at $20^{\circ} \mathrm{C}$ and constant light. When the first leaves of the seedlings were $1 \mathrm{~cm}$ long, the seedlings were frozen for later electrophoretic analysis. This stage was called the 2 nd stage to relate to the developmental stage 
analyzed in Experiment 2.

Horizontal polyacrylamide gel electrophoresis was performed for four enzyme systems: esterases (EST, E.C. 3.1.1.1), glutamate oxaloacetate transaminases (GOT, E.C. 2.6.1.1), superoxide dismutases (SOD, E.C. 1.15.1.1), and malate dehydrogenases (MDH, E.C. 1.1.1.37). Electrophoretic separation on 6 and $8 \%$ polyacrylamide gels and buffers described by Scandalios (1969) were used for EST; 6 and 7\% polyacrylamide gels and buffers by Roose and Gottlieb (1976) for MDH and SOD, and 7\% polyacrylamide gels and buffers by Brown (1983) for GOT. The gels were run at $10 \mathrm{~V} / \mathrm{cm}$ until the front line migrated $8 \mathrm{~cm}$ from the starting point. Staining procedures for EST were those described by Scandalios (1969), including $\beta$-naphthyl acetate. MDH and SOD were revealed following Brewer (1970) with modifications for SOD, which was stained with a glutamate dehydrogenase-staining mixture and incubated under illumination. GOT was developed according to Vallejos (1983), without pyridoxal-5-phosphate. A total of 237 seedlings from the 95 strains were analyzed for three tissues: first leaves, roots and endosperm. The genes and alleles were determined by Ferreira and Cavalli-Molina (1994).

\section{Experiment 2}

About seven individuals of each of $12 \mathrm{H}$. euclaston strains were analyzed (Table 2) for several tissues from five developmental stages: 1 st stage - recently germinated seedlings, showing root development (roots and endosperm); 2nd stage - seedlings with the first leaves $1 \mathrm{~cm}$ long (roots, endosperm and first leaves); 3rd stage - seedlings with the appearance of the second leaves (roots, first and second leaves); 4th stage - young plant with five leaves (top, middle and base from the first and fourth leaves), and 5th stage - plant with the early signs of flowering (first, second and third leaves from the first tiller showing the first inflorescence exposed). The early stages were obtained through germination on Petri dishes with the same conditions used in Experiment 1. The young and mature plants were obtained by germination on pots with soil. The germination and development of each plant were carefully followed to ensure that each stage analyzed was exactly the same for all individuals. The same amount of tissue for all samples was used in each developmental stage, ensuring no interference of tissue quantity in enzymatic activity visualization.

Table 2. Strains of the three populations analyzed in Experiment 2 and collection sites.

\begin{tabular}{lll}
\hline Population & Site (country) & Strains \\
\hline 2 & $\begin{array}{l}\text { Alegrete, RS, BR; on an unpaved road, 44 km from } \\
\text { site 1; 5 plants }\end{array}$ & HW3455; HW3457; HW3461; SCM1055; SCM1169 \\
4 & $\begin{array}{l}\text { Alegrete, RS, BR; km 542 of BR 290 highway; 1 plant } \\
\text { Quaraí, RS, BR; on BR 377 highway, }\end{array}$ & HW3149 \\
5 & SCM1181; SCM1184; SCM1185; SCM1193; SCM1211; SCM 1212 \\
& & \\
\hline
\end{tabular}

For abbreviations, see legend to Table 1.

For enzyme extraction, small pieces of equivalent size of each tissue were cut and ground with $15 \mu \mathrm{L}$ extraction buffer (Scandalios, 1969), using an acrylic plate and glass pestles. The homogenized extracts were absorbed onto filter paper (Whatman 3MM, 2 x $10 \mathrm{~mm}$ ) and immediately applied onto the gels. The whole procedure was performed on ice. 
Electrophoretic analyses were the same as used in Experiment 1 but resorting only to the best condition for EST (6\% gels). The band with relative migration (RM) given in the Results section are those obtained in 6\% gels for EST and in 7\% for GOT and SOD. The staining procedures were also the same as used in Experiment 1.

\section{RESULTS}

In Experiment 1, where only one developmental stage was analyzed (2nd stage), most of the $H$. euclaston plants showed the same regulatory pattern, i.e., the same genes were active when the same tissue in a specific ontogenetic stage was analyzed. Nevertheless, regulatory differences could be detected between some strains, i.e., some genes were active in some strains but not in others, under identical conditions. Besides the dissimilarities between strains, differences between sib-plants within the same strain were also detected. These regulatory differences were found for EST, GOT and SOD, but not for MDH.

Regulatory differences between strains are clearly seen in Figure 1. This case concerns a set of EST isoenzymes with $\alpha$-naphthyl activity and RM of $0.86,0.82,0.77$, and 0.73 , which were detected in seedlings of eight strains from the 2nd stage in Experiment 1 . These bands
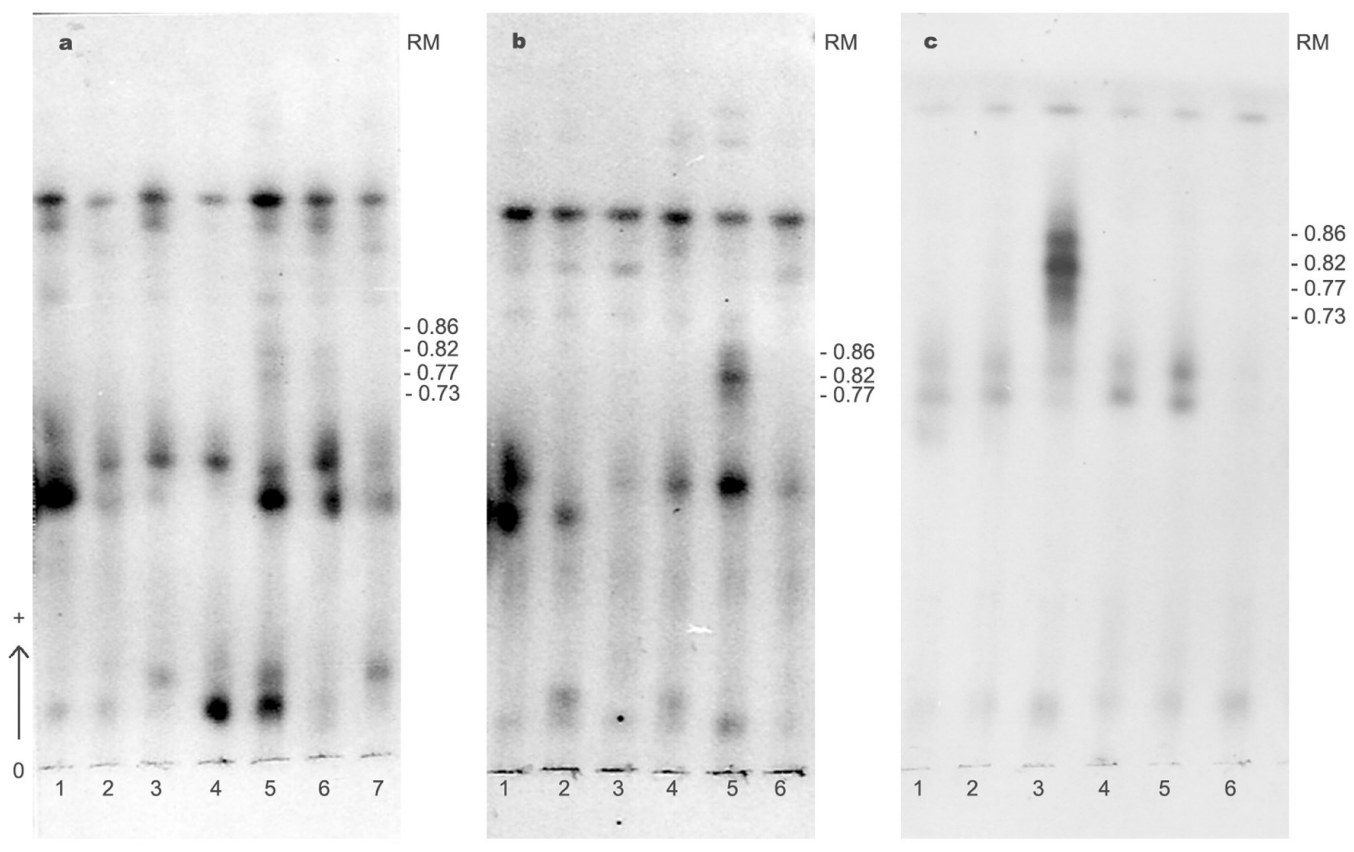

Figure 1. Esterase (Est) patterns of Hordeum euclaston. a. First leaves from seven strains from the 2nd developmental stage showing activation of additional bands with relative migration (RM) 0.86, 0.82, 0.77, and 0.73 in strain HW3179 (slot 5) and of the bands with RM 0.82 and 0.77 in strain SCM1112 (slot 6). b. First leaves of six strains from the 2nd stage showing three extra-bands with RM of 0.86, 0.82, and 0.77 in strain HW3297 (slot 5). c. First, second and third leaves (in this order) of the first tiller with inflorescence from the 5 th stage of two strains showing bands with RM of $0.86,0.82,0.77$, and 0.73 as active only in the third leaves in the first strain (SCM1211) (slot 3). The genetic control of the other isoenzymes is described in Ferreira and Cavalli-Molina (1994). 
were observed only for the first leaves and roots. In Experiment 1, these four bands were found together only in one strain (HW3179) (Figure 1a, slot 5); three strains (HW3089, HW3188, SCM1112) displayed only the two intermediate bands (RM of 0.82 and 0.77 ; Figure 1a, slot 6); two strains (HW3132, HW3297) showed three of these isoenzymes (RM of 0.86, 0.82, and 0.77) (Figure 1b, slot 5), and two others (HW3139, SCM1111) exhibited another band pattern (RM of 0.86 and 0.82 ).

The other 87 strains analyzed in Experiment 1 showed total absence of these isoenzymes. The band patterns observed in these strains cannot be explained as isoenzymes controlled by alleles from a single gene, but they fit well as phenotypes of homozygous plants responding to different controls of gene activation.

Experiment 2 was carried out in order to test the hypothesis that different strains or sib-plants from the same strain of $H$. euclaston showed the same structural gene alleles activated at different developmental stages. In relation to the patterns of EST bands discussed above, three strains (HW3455, HW3457 and SCM1211) showed irregular gene activation during development. In strain SCM1211, for example, of the 13 sib-seedlings analyzed in the 2nd stage, one showed three of the four already mentioned isoenzyme bands (RM 0.86, 0.82 and 0.77 ) in the first leaves; two showed two isoenzyme bands (RM of 0.82 and 0.77 ), and two others showed only one isoenzyme band (RM of 0.82 ). Moreover, one plant of this strain exhibited the four isoenzyme bands (RM of $0.86,0.82,0.77$, and 0.73 ) in the third leaves from the first tiller with inflorescence (5th stage) (Figure 1c, slot 3).

A similar result could be detected concerning the Est2 and Est 3 genes of $\mathrm{H}$. euclaston. These two genes produce isoenzymes with $\beta$-naphthyl esterase activity and RM of 1.10 and 1.05, respectively. In Experiment 1, the Est2 and Est3 isoenzyme bands were found restricted to first leaves of some strains (Figure 2a, slots 4, 7 and 10), but they were not present in the other strains analyzed (Figure 2a, slot 1). Differences in Est2/Est3 patterns between sib-seedlings from four strains were also detected in Experiment 1 . As can be seen in Figure 2b, the sib-seedlings of strain SCM1112 showed different patterns: three seedlings displayed the two isoenzyme bands (bands indicated by arrows in slots 6, 7 and 8), while five did not (slots 1 to 5).

In the analyses of Experiment 1, Est2 and Est3 isoenzymes always occurred together with the same intensity (none with secondary band characteristics), suggesting that the two genes respond to only one regulatory control. Sib-seedlings analysis from strain HW3171 showed the same pattern with the two bands for Est2 and Est3 (Supplementary material - S1). This absence of segregation corroborates that this pattern does not correspond to heterozygotes, where these two electromorphs represent alleles from one structural gene. In another test with this same strain, seven sib-seedlings with first leaves whose length varied from 0.85 to $2.35 \mathrm{~cm}$ were analyzed to determine whether the presence or the absence of these two isoenzymes could be the result of small differences in the developmental stage of each seedling. All the seedlings analyzed showed the same isoenzyme pattern with these two isoenzyme bands (data shown in Ferreira and Cavalli-Molina, 1994), allowing us to conclude that the presence or the absence of these bands among distinct strains is not due to ontogenetic differences, but probably to regulatory differences in the same developmental stage.

In the ontogenetic analysis carried out in Experiment 2, it was possible to demonstrate that the differences in isoenzyme gene activation between strains or sib-plants, regarding the Est2 and Est3 genes, are due to regulatory differences between plants, and not derived from 

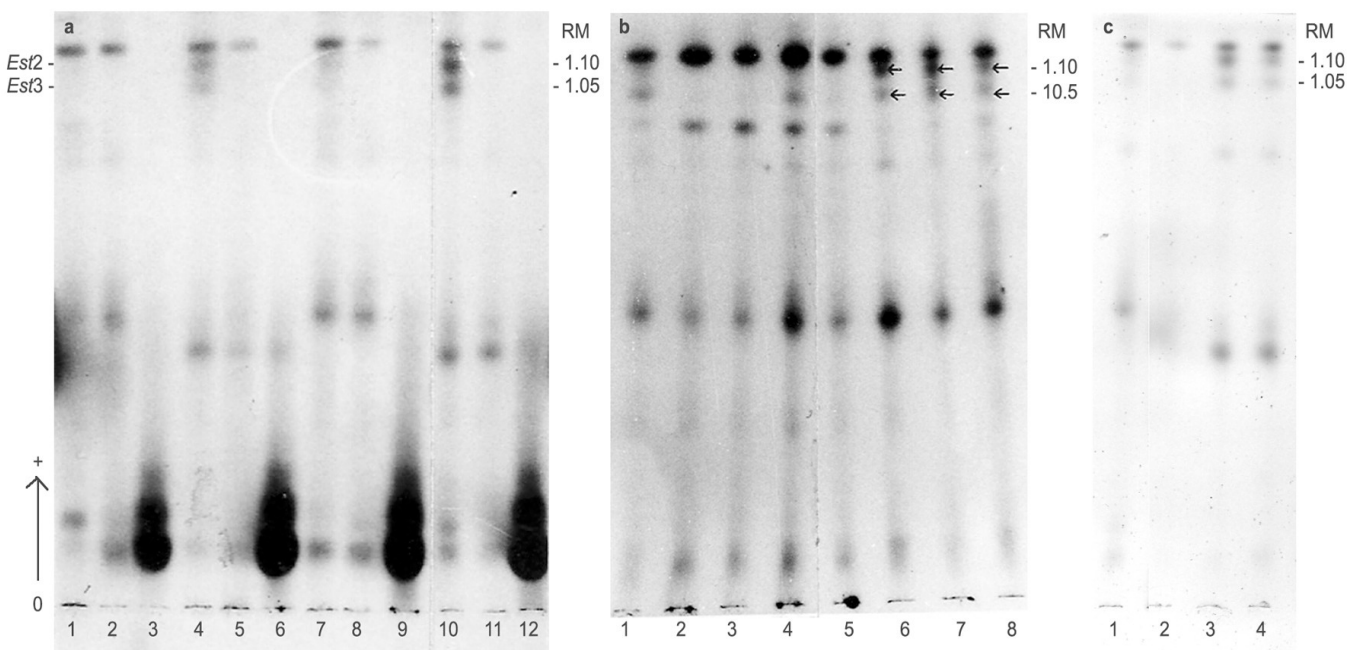

Figure 2. Esterase (Est) patterns of strains of Hordeum euclaston. a. First leaves, roots, and endosperm (in this order) from four strains from the 2nd stage, demonstrating differences in activation and repression in the Est 2 and Est3 genes in the first leaves (slots 1, 4, 7, and 10). b. First leaves from eight sib-seedlings from the 2nd stage of strain SCM1112, showing differences in activation in the Est 2 and Est 3 genes (bands indicated by arrows showed $\beta$-naphthyl esterase activity and are controlled by the Est 2 and Est 3 genes); the bands with the same Est 3 relative migration (RM), which are seen in the slots 1 to 5 , exhibit $\alpha$-naphthyl esterase activity and correspond to another gene. c. First leaves from the 2nd stage of strain SCM1193 (slot 1), showing the presence of the Est2 and Est3 bands while strain SCM1181 shows the absence of these bands in the same tissue from the same stage (slot 2) but presence of the same bands in the first leaves from the 3rd and 4th stages (slots 3 and 4). The genetic control of the other isoenzymes is described in Ferreira and Cavalli-Molina (1994).

structural gene polymorphism. Figure 2c shows the patterns of first leaves from the 2nd stage of two strains: SCM1193 with the presence of Est2 and Est3 bands (slot 1) and SCM1181, in which these two genes were not active (slot 2). Yet, strain SCM1181 did in fact exhibit active Est2 and Est3 genes, but in the first leaves from the 3rd and 4th stages (slots 3 and 4). This result reinforces the same conclusion: the presence or absence of these isoenzyme bands in some strains or sib-plants is due to regulatory differences. The other four strains analyzed in Experiment 2 (HW3455, HW3457, SCM1211, and SCM1212) showed similar results (Supplementary material - S2), and other EST genes (Est4, Est5, Est9, and Est10) also showed regulatory differences between strains or sib-plants (data not shown).

For the GOT system, five gene products were detected in seedlings from the 2nd stage of H. euclaston. Got 2 was the only polymorphic gene: the most common allele $\left(G o t 2^{I}\right)$ is responsible for the isoenzyme, which forms the band with RM of 1.33 (Figure 3, slots 2 to 5), while the rarer one $\left(G o t 2^{2}\right)$ produces the isoenzyme that generates the band with RM 1.32. Nevertheless, one seedling from two strains (HW3080 and HW3173) showed the absence of the isoenzyme bands with RM 1.33 and 1.32, but exhibited two other isoenzyme bands on this gel region (RM 1.24 and RM 1.36, Figure 3, slot 1 and 6, respectively). No band revealed characteristics of secondary isoenzyme.

The occurrence of this different pattern could not be easily explained by classic Mendelian segregation because many rare events occurring simultaneously should have taken 


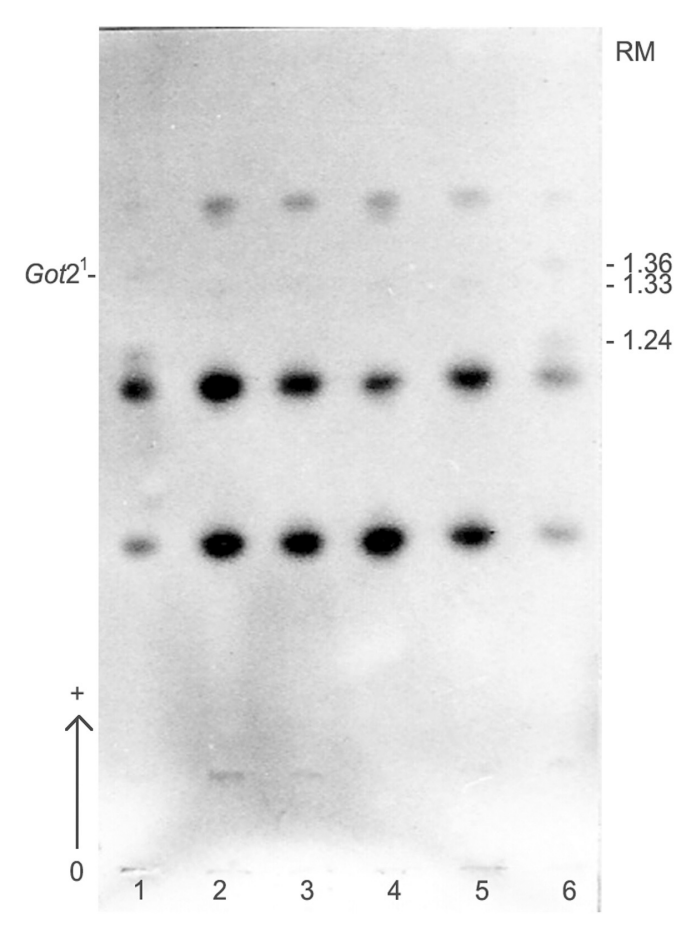

Figure 3. Glutamate oxaloacetate transaminase (Got) patterns in first leaves of five sib-seedlings from the 2 nd stage of strain HW3173 of Hordeum euclaston. The seedlings of slots 2 to 5 exhibit the common allele of the Got 2 gene while the seedling of slot 1 (repeated in slot 6) shows a singular pattern of bands with relative migration (RM) of 1.36 and 1.24. The genetic control of the other isoenzymes is described in Ferreira and Cavalli-Molina (1994).

place, such as: i) these two seedlings would be the only heterozygous plants detected in $H$. euclaston; ii) these two cases would be the only events of out-crossing detected in this species; iii) these two heterozygote individuals would show two very rare alleles. Besides, these differences are not ontogenetic modifications, because these two seedlings with this atypical pattern had the same age and the same leaf length.

The ontogenetic analyses showed other regulatory differences in this enzyme system. The isoenzyme bands formed by the Got 3 and Got 4 genes showed a typical intensity for each tissue and developmental stage: Got3 band was more intense than Got 4 in leaves from all stages, and Got 3 was relatively more intense in the 1 st and 2 nd stages than in the 3rd one in roots. Exceptions in these relative intensities were found in eight strains (HW3457, HW3455, HW3461, SCM1169, SCM1181, SCM1193, SCM1211, and SCM1212) (Supplementary material - S3).

Differences in gene activation between individuals were also detected in the SOD system in the analyses of Experiment 1. The $\operatorname{Sod} 7$ gene showed differences between individuals when the same tissue and developmental stage were analyzed. This monomorphic gene is responsible for the synthesis of the isoenzyme, which corresponds to the band with RM of 0.40 . In the 2 nd stage, this isoenzyme was usually restricted to roots, but it was also detected in the first leaves from some seedlings as a less intense band (Figure 4a). 



Figure 4. Superoxide dismutase (Sod) patterns in plants of Hordeum euclaston. a. First leaves (slots 1, 3, 5) and roots (slots 2, 4, 6) from the 2nd stage of three strains, which show the common pattern in which the Sod7 gene is active in roots and sometimes detected in the first leaves as a less intense band. b. First leaves (slots 1 and 2) and roots (slots 3 and 4) from two sib-seedlings from the 2nd stage of strain SCM1113, demonstrating differences in the expression of the Sod9 gene (band with relative migration (RM) of 1.22), which is not active in the first leaves of the first seedling (slot 1) but is expressed in this same tissue and stage in the second seedling (slot 2). The genetic control of the other isoenzymes is described in Ferreira and Cavalli-Molina (1994).

During development, Sod7 was detected in first leaves from the 1st to the 4th stage and in roots from the 1 st to the 3 rd stage, forming the same band with RM of 0.40 . Although three strains (HW3457, SCM1185 and SCM1212) indeed maintained the band with RM of 0.40 in roots, their first leaves showed instead another isoenzyme band (RM of 0.35) (Supplementary material - S4).

Still for the SOD system, the Sod 9 gene showed regulatory differences. This gene is monomorphic and it produces an isoenzyme (band with RM of 1.22), usually active in the first leaves and roots starting at the 2nd stage. The analysis of the progeny of strain SCM1113 showed four sib-seedlings, which had the band with RM of 1.22 in the first leaves from the 2nd stage, and three, which did not show it in this tissue, although this isoenzyme has always been present in the roots of all these seedlings. In Figure 4b, it is possible to see one seedling from this strain (SCM1113) without this isoenzyme band in its first leaves (slot 1) and its sib with this band in the same tissue and stage (slot 2). Both seedlings showed this isoenzyme band in their roots (slots 3 and 4). The same type of alteration for $\operatorname{Sod} 9$ gene expression was also found in the progeny of another strain (EKS3H). 


\section{DISCUSSION}

Several authors have emphasized for a long time that mutations in regulatory genes play an important role in the speciation process (Palopoli and Patel, 1996). Nevertheless, until recently, little or no variation in these control genes was demonstrated to occur within species. The rule was that the development pattern was fixed for the species, which means that all individuals from the same species could show the same active gene in a specific tissue or organ at a given developmental stage. During development, genes would be expressed and repressed in a fixed way within the species (Kuhlemeier et al., 1987).

In the present research, differences in activation of specific structural genes were found to be in the autogamous grass H. euclaston from Rio Grande do Sul State, Southern Brazil. The genetic variability of these populations was previously analyzed by Ferreira and Cavalli-Molina (1994). These authors described the genetic control of the principal loci for the same four isoenzyme systems that were investigated in the present paper. Here, the attention was directed specifically to isoenzymes that showed variations in their presence and/or level of activity comparing different ontogenetic stages/tissues of seemingly genetically identical individuals. These isoenzymes, as described in the Results section, showed an atypical behavior since individuals show differences in the activation of these genes. These differences cannot be explained in these analyses by gene activation at different developmental stages, because the seedlings and plants analyzed in each experiment were rigorously followed. The methodology employed made sure that all $H$. euclaston individuals were analyzed at a very specific and clearly defined stage of their development. Therefore, the dissimilarities observed must have originated exclusively from differences between strains and/or sib-plants with regard to activation or repression of structural genes that produce the isoenzymes at a given ontogenetic stage. The individuals of this species that did not show a particular isoenzyme in a specific tissue and/or ontogenetic stage clearly possess the structural gene allele, because the same isoenzyme was detected in another tissue and/or developmental stage of a sib-plant that possesses the same genotype. This indicates that the same structural gene is subject to different activation patterns in different individuals of this species.

To explain these activation differences, two possibilities can be considered. First, differences in activation and repression of specific genes could be a result of regulatory gene mutations. Regulatory mutants have already been found in some species (Riechmann and Meyerowitz, 1997; Labate et al., 1999) and the identification of these mutants in which the development program is altered is very important to the utter understanding of the nature of the genetic relationship between the structural genes and the respective regulatory genes (Sheridan, 1988). This possibility could explain the differences between strains that have different genotypes. Nevertheless, this situation is not suitable to explain differences between sib-plants, which share the same structural alleles (Ferreira and Cavalli-Molina, 1994) and, consequently, must share the same regulatory genes. As the existence of allele differences between sib-plants in this species is very improbable, these results lead to a second possibility, which considers the occurrence of differential regulatory activation. According to this idea, sib-plants would have the same regulatory alleles, as well as the same structural alleles. Thus, the activation and repression of the structural genes may be due to a flexible gene expression modulation, possibly as a result of epigenetic influences, which have been suggested as an important, and maybe favored, mechanism of phenotypic variation in clonally propagated 
plants (Grant-Downton and Dickinson, 2006). In this sense, it is attractive to speculate that the great variability found in morphological characters for $H$. euclaston (von Bothmer et al., 1982) could represent the same kind of variation found in the isoenzyme patterns described herein. Such situation has already been observed in Relbunium hypocarpium, another self-fertilizing species. The phenotypic variability detected in $R$. hypocarpium also arose from regulatory differences because some individuals of this species, which did not show a particular isoenzyme at a specific ontogenetic stage at which it was commonly found, surely had the structural gene, since the same isoenzyme was detected in another developmental stage. Therefore, the same structural gene alleles present in all the plants are subject to different regulatory mechanisms in different individuals of this species (Schiengold, 1985; Freitas, 1989). Also, the study of the genetic diversity of the genus Hemerocallis with AFLP markers (Tomkins et al., 2001) showed that during its history of intensive breeding genetic diversity has dramatically decreased, although its plasticity and phenotypic variation have remained high, suggesting that epigenetic influences may be an important source of variability (Grant-Downton and Dickinson, 2006).

More studies are necessary to draw a conclusion as to whether this situation is exclusive to $H$. euclaston and other autogamous species or more likely to be observed in other species. However, the main fact is that this differential regulatory activation improves the organism's phenotypic variability, which seems to be helpful in the adaptation to variations in its environment. Purugganan (2000) emphasizes that regulatory genes may play important roles in physiological adaptation by controlling the temporal and spatial expression of structural enzyme genes. As plants are much more susceptible to their surroundings than animals (van Kleunem and Fischer, 2005), it is likely that this regulatory flexibility is more frequent in plant species.

What is the importance and mechanism of this regulatory flexibility with the resulting differential gene expression patterns? As a consequence of their sessile nature and as part of their interactions with pathogenic and beneficial organisms, plants accumulate thousands of small molecules with specialized functions (Field et al., 2006). Many phytochemicals (secondary metabolites), not essential to plant survival, can provide adaptation to ecological alterations. Thus, the production of these metabolites by some plants, as a response to environmental modifications prior to seed collection, is the ultimate result of adaptive phenotypic plasticity (Grotewold, 2005).

Another possibility would be the natural physiological differences in seeds, regarding their position within the ear and/or tiller (distinctive microenvironments). In species of the Hordeum genus, within-plant variability results from differences within the ears and between the tillers of a plant (Riggs and Kirby, 1978). Jacquard et al. (2006) demonstrated that the position of the tiller on the plate of tillering has an impact on both the number of regenerated plantlets and the percentage of green plants in barley. They found that the anther response decreased when the donor spike originates from the fourth tiller in relation to main shoot. The authors argued that it is likely that there is a negative gradient of assimilates in the plate from the main shoot to the fourth tiller, especially considering nutrients originating from the roots. This is supported by previous works demonstrating that tillering is affected by internal factors, due to an increase in competition among the plant organs for carbon assimilates or nitrogen compounds (Kirby et al., 1985). This means that the spike on the fourth tiller is not as well supplied with nutrients as that on the main shoot; in other words, the position of the spike on the plant may have an impact on spike physiology. 
The variability resulting from differences within the ears has been observed in many species (Wulff, 1986). In wheat, grain weight and macronutrient and micronutrient contents of the grains distal to the rachis are reported to be lower than those of grain more proximal to the rachis (Liu et al., 2006). In Europe, the malting barley cultivars most commonly grown have a two-row ear, because the six-row type has unacceptable variation in grain size (Ellis and Marshall, 1998). The variation in seed size is a result of its position on the maternal plant (i.e., seeds vary in size due to the position effects within fruit or inflorescence). In Hordeum vulgare ssp. spontaneum, it was observed that initial seed size affected germination time, seedling growth rate and the number of seeds produced. There were, however, no differences in the means of the sizes of seeds produced by genetically identical individuals, which can be explained if the position effects are regenerated by seeds of different sizes. It has been proposed that it is a particular distribution of sizes rather than a particular seed size that characterizes a genotype (Giles, 1990). Ellis and Marshall (1998) studied the variation in grain weight and germination time with position on the ear and showed that germination time increased systematically from the bottom to the top of ear and was, to some extent, affected by grain weight. Voltas et al. (1998) detected that in six-row barley the central grains have largest inherent weight potential. A possible explanation was a physical restriction in growth by the lemma and palea of lateral florets, which might have limited final grain weight. Probably, anatomical differences in the vascular bundles serving the florets were also involved (Kirby and Rymer, 1975). Kirby and Rymer (1975) observed that the vascular bundles feeding the lateral spikelets of barley were smaller compared to those of the central spikelets. de Kroon et al. (2005) proposed that the response of a plant to its environment is the sum of all modular responses (meristems, leaves, branches, etc.) to their local conditions plus all interaction effects that are due to integration, and they argued that in modular organisms, not only growth and development, but also environmentally induced changes in the expression of traits (i.e., phenotypic plasticity) take place at a module level. Phenotypic plasticity refers to the ability of a genotype to exhibit alternative morphological, behavioral and physiological characteristics in response to environmental conditions (Fordyce, 2006).

Thus, physiological differences between $H$. euclaston individuals in response to small environmental differences regarding their position as seeds within the ear and the variation in environmental conditions experienced by each ear still on the plant are possible explanations for the differential regulatory activation observed among strains and among sib-plants of the same strain, when the same or different ontogenetic stages were compared.

The observed differences in gene activity between individuals from a single species at a specific developmental stage may be common in autogamous plants, where the reproduction system restricts gene flow and, thus, overall genetic variability, enabling each strain to follow independent evolutionary lines. This kind of variation may be especially important to autogamous plants, representing a possible source of phenotypic plasticity. On the other hand, it is important to emphasize that these differences in the isoenzyme patterns were not the most common found in H. euclaston (Ferreira and Cavalli-Molina, 1994), and thus, seed positions within the ear and/or tiller are not the only factors influencing gene expression.

If this situation of differential regulatory activation is more frequent and occurs in a great number of species, it will be necessary to rethink the analysis based on isoenzyme patterns without the knowledge of the genetic control of the electromorphs. This concern arises because some of the differences observed would not be due to gene mutations, either in structural or in regula- 
tory genes, but only due to a gene activation event based on minute environmental differences.

Molecular population geneticists should expand the number of population-level studies of regulatory genes in order to obtain a more comprehensive picture of the diversity patterns of these genes. Moreover, it is necessary to investigate this kind of variability in both self-fertilizing and allogamous species and determine whether the regulatory flexibility described in the present paper is actually a feature of the first kind of plants or a more general picture of molecular adaptation. Thus, one question that remains is: What are the relative contributions of epigenetic and genetic heritage in the overall phenotypic variation in plants? Furthermore, many related questions still need answers: What is the actual contribution of regulatory genes in intraspecific phenotypic variation? How important is the differential regulatory activation (by controlling the temporal and spatial expression) of structural enzyme genes to plant physiological adaptation? The present data suggest that this type of regulation may play an important role in the phenotypic diversification of $H$. euclaston, and support the notion that it may be especially important within autogamous species, opening new horizons for an emerging molecular ecology of adaptation.

\section{ACKNOWLEDGMENTS}

We would like to thank Helga Winge and Eliane Kaltchuk dos Santos, Ph.D. (Genetics Department of Universidade Federal do Rio Grande do Sul), for providing seeds of many plants of Hordeum euclaston.

\section{REFERENCES}

Bramley PM (2002). Regulation of carotenoid formation during tomato fruit ripening and development. J. Exp. Bot. 53: 2107-2113.

Brewer G (1970). An Introduction to Isoenzyme Techniques. Academic Press, New York.

Brown AHD (1983). Barley. In: Isoenzymes in Plants Genetics and Breeding, Part B (Tanksley SD and Orton TJ, eds.). Elsevier Science Publisher BV, Amsterdam, 57-77.

de Kroon H, Huber H, Stuefer JF and van Groenendael JM (2005). A modular concept of phenotypic plasticity in plants. New Phytol. 166: 73-82.

Ellis RP and Marshall B (1998). Growth, yield and grain quality of barley (Hordeum vulgare L.) in response to nitrogen uptake: II. Plant development and rate of germination. J. Exp. Bot. 49: 1021-1029.

Ferreira CAS and Cavalli-Molina S (1994). Self-fertilization and absence of heterozygotes in Hordeum euclaston (Gramineae). Rev. Bras. Genet. 17: 89-95.

Field B, Jordan F and Osbourn A (2006). First encounters - deployment of defence-related natural products by plants. New Phytol. 172: 193-207.

Fordyce JA (2006). The evolutionary consequences of ecological interactions mediated through phenotypic plasticity. $J$. Exp. Biol. 209: 2377-2383.

Freitas LB (1989). Contribuição da Regulação Gênica para a Variabilidade Isoenzimática de GOT (Glutamato-oxaloacetato Transaminase) em Relbunium hypocarpium (Rubiaceae). Master's thesis, Universidade Federal do Rio Grande do Sul, Porto Alegre.

Giles BE (1990). The effects of variation in seed size on growth and reproduction in the wild barley Hordeum vulgare ssp. spontaneum. Heredity 64: 239-250.

Grant-Downton RT and Dickinson HG (2006). Epigenetics and its implications for plant biology 2. The 'epigenetic epiphany': epigenetics, evolution and beyond. Ann. Bot. 97: 11-27.

Grotewold E (2005). Plant metabolic diversity: a regulatory perspective. Trends Plant Sci. 10: 57-62.

Jacquard C, Asakaviciute R, Hamalian AM, Sangwan RS, et al. (2006). Barley anther culture: effects of annual cycle and spike position on microspore embryogenesis and albinism. Plant Cell Rep. 25: 375-381.

Jalal Kamali MR and Boyd WJR (1999). Growth, Development and Yield Determination in Barley. Proceedings of the 9th 
Australian Barley Technical Symposium, 12-16 September, Melbourne.

Kirby EJM and Rymer JL (1975). The vascular anatomy of the barley spikelet. Ann. Bot. 39: 205-211.

Kirby EJM, Appleyard M and Fellowes G (1985). Leaf emergence and tillering in barley and wheat. Agronomie 5: 193-200.

Koes R, Verweij W and Quattrocchio F (2005). Flavonoids: a colorful model for the regulation and evolution of biochemical pathways. Trends Plant Sci. 10: 236-242.

Kuhlemeier C, Green PJ and Chua NH (1987). Regulation of gene expression in higher plants. Annu. Rev. Plant Physiol. 38: 221-257.

Labate JA, Biermann CH and Eanes WF (1999). Nucleotide variation at the runt locus in Drosophila melanogaster and Drosophila simulans. Mol. Biol. Evol. 16: 724-731.

Larsen PF, Nielsen EE, Williams TD, Hemmer-Hansen J, et al. (2007). Adaptive differences in gene expression in European flounder (Platichthys flesus). Mol. Ecol. 16: 4674-4683.

Liu ZH, Wang HY, Zhang GP, Chen PD, et al. (2006). Genotypic and spike positional difference in grain phytase activity, phytate, inorganic phosphorus, iron, and zinc contents in wheat (Triticum aestivum L.). J. Cereal Sci. 44: 212-219.

Lundgren MR and Sultan SE (2005). Seedling expression of cross-generational plasticity depends on reproductive architecture. Am. J. Bot. 92: 377-381.

Palopoli MF and Patel NH (1996). Neo-Darwinian developmental evolution: can we bridge the gap between pattern and process? Curr. Opin. Genet Dev. 6: 502-508.

Purugganan MD (2000). The molecular population genetics of regulatory genes. Mol. Ecol. 9: 1451-1461.

Riechmann JL and Meyerowitz EM (1997). MADS domain proteins in plant development. Biol. Chem. 378: 1079-1101.

Riggs TJ and Kirby EJM (1978). Developmental consequences of two-row and six-row ear type in spring barley: 1. Genetical analysis and comparison of mature plant characters. J. Agric. Sci. 91: 199-205.

Roose ML and Gottlieb LD (1976). Genetic and biochemical consequences of polyploidy in Trogopogon. Evolution 30: 818-830.

Scandalios JG (1969). Genetic control of multiple molecular forms of enzymes in plants: a review. Biochem. Genet. 3: 37-79.

Schiengold M (1985). Efeito da Regulação Gênica na Variabilidade Isoesterásica de Relbunium hypocarpium (Rubiaceae). Master's thesis, Universidade Federal do Rio Grande do Sul, Porto Alegre.

Sheridan WF (1988). Maize developmental genetics: genes of morphogenesis. Annu. Rev. Genet. 22: 353-385.

Sultan SE (2005). An emerging focus on plant ecological development. New Phytol. 166: 1-5.

Tomkins JP, Wood TC, Barnes LS, Westman A, et al. (2001). Evaluation of genetic variation in the daylily (Hemerocallis spp.) using AFLP markers. Theor. Appl. Genet. 102: 489-496.

Vallejos E (1983). Enzyme Activity Staining. In: Isoenzymes in Plants Genetics and Breeding, Part A (Tanksley SD and Orton TJ, eds.). Elsevier Science Publisher BV, Amsterdam, 469-516.

van Kleunen M and Fischer M (2005). Constraints on the evolution of adaptive phenotypic plasticity in plants. New Phytol. 166: 49-60.

Voltas J, Romagosa I and Araus JL (1998). Growth and final weight of central and lateral barley grains under Mediterranean conditions as influenced by sink strength. Crop Sci. 31: 84-89.

von Bothmer R, Jacobsen N, Jorgensen RB and Nicora E (1982). Revision of the Hordeum pusillum group. Nordic J. Bot. 2: $307-321$.

Walbot V (1996). Sources and consequences of phenotypic and genotypic plasticity in flowering plants. Trends Plant Sci. 1: 27-32.

Weinig C and Delph LF (2001). Phenotypic plasticity early in life constrains developmental responses later. Evolution 55: 930-936.

Whitehead A and Crawford DL (2006). Variation within and among species in gene expression: raw material for evolution. Mol. Ecol. 15: 1197-1211.

Wulff RD (1986). Seed size variation in Desmodium paniculatum: II. Effects on seedling growth and physiological performance. J. Ecol. 74: 99-114. 


\section{SUPPLEMENTARY MATERIAL}

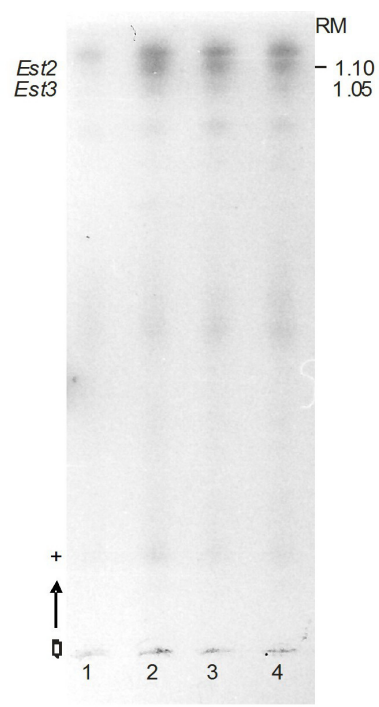

S1. Representative gel of sib-seedling analysis. First leaves from the 2nd stage from sib-seedlings of strain HW3171 (slot 1 to 4) showing the occurrence of Est2 and Est3 isoenzyme bands together with similar intensity. $E s t=$ esterase $; \mathrm{RM}=$ relative migration.

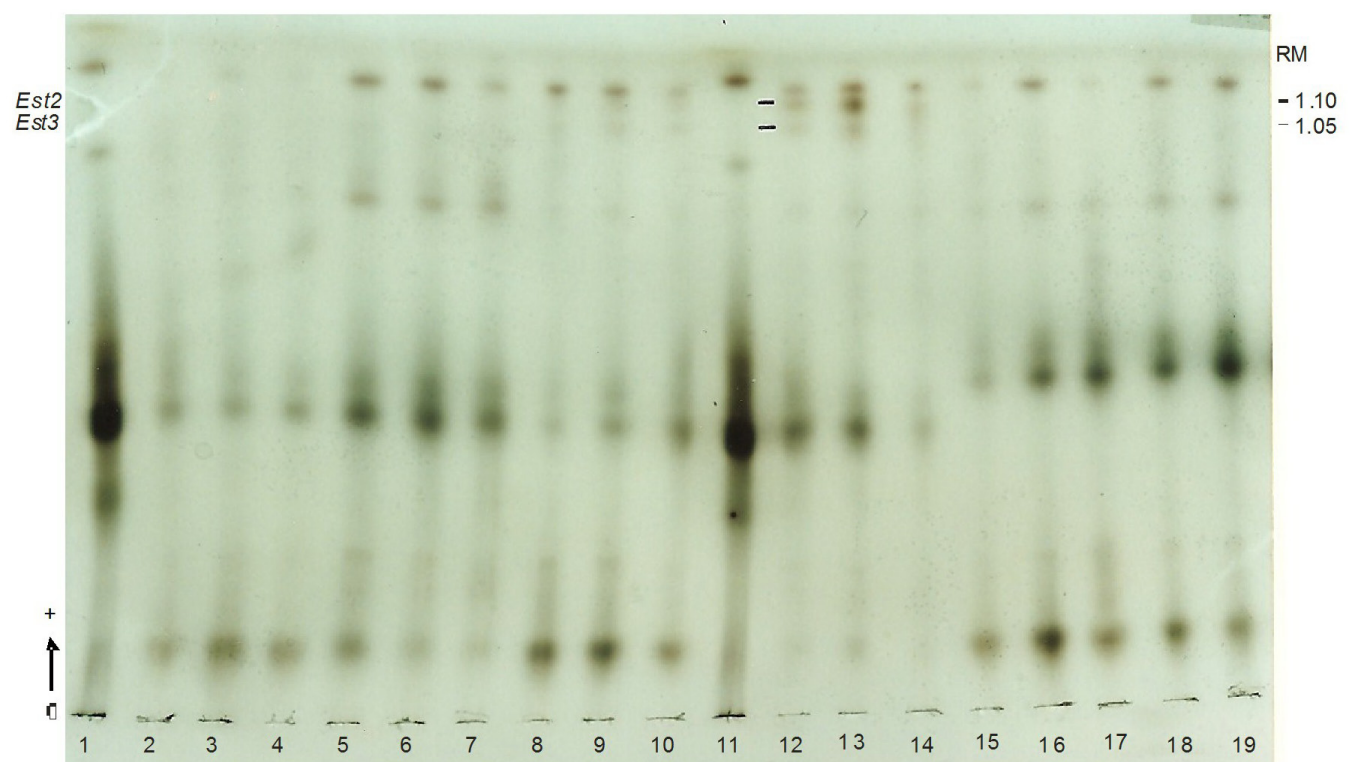

S2. Gel of different strains from the 4th stage. Patterns of esterase (Est) of Hordeum euclaston, from top (slots 2, 8 and 15), medium (slots 3,9 and 16) and base (slots 4,10 and 17) from the first leaves and top (slots 5, 12 and 18), medium (slots 6, 13 and 19) and base (slots 7, and 14) from the fourth leaves, of the plants from the 4th stage from strains SCM1185 (slots 2 to 7), HW3455 (slots 8 to 10 and 12 to 14) and SCM 1212 (15 to 19). Control (slots 1 and 11): H. vulgare. Loci Est2 and Est3 are active only in strain HW3455. RM = relative migration. 

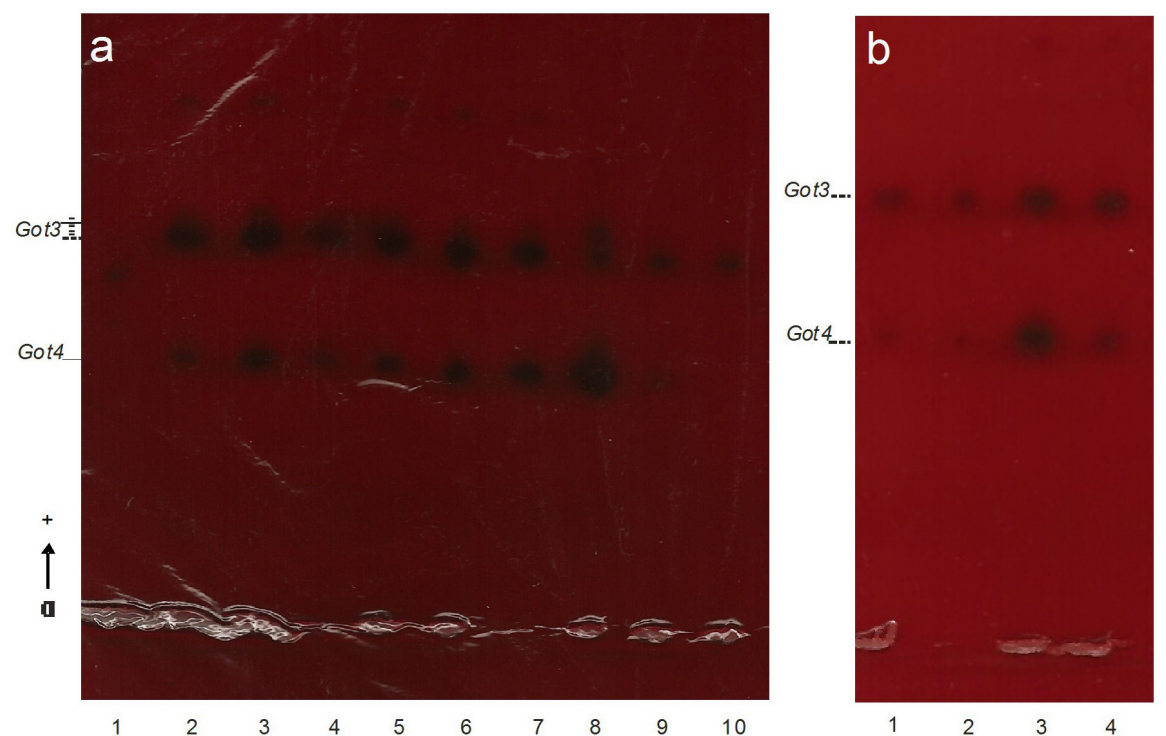

S3. Representative gels showing differences in relative intensities of the bands. a. Patterns of glutamate oxaloacetate transaminase (Got) of Hordeum euclaston, of top (slots 2 and 8), medium (slots 3 and 9) and base (slots 4 and 10) from the first leaves and top (slot 5), medium (slot 6) and base (slot 7) from the fourth leaves, of two plants (the first plant slots 2 to 7, the second plant slots 8 to 10) from the 4th stage from strain HW3457. Control (slot 1): H. vulgare. Note the higher activity of locus Got3, except for the top of the 1st leaf of the 2 nd plant (slot 8). b. First leaves from the 2 nd stage of strain HW3455 also showing atypical relative intensities: Got4 band is more intense than Got3 band (slot 3).

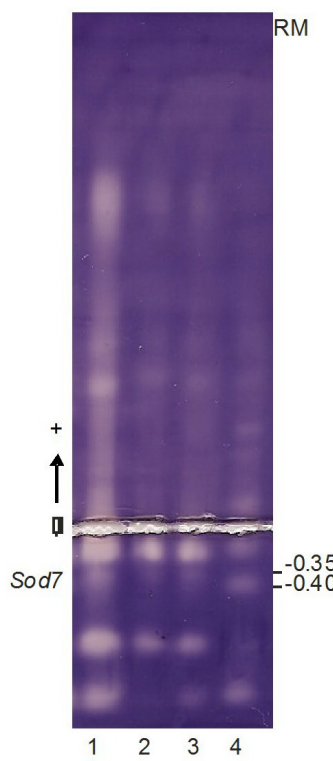

S4. Representative gel of SCM1185. First leaves (slots 1 to 3 ) and root (slot 4) from the 2nd stage of strain SCM1185. Although the band of relative migration (RM) -0.40 was present in roots, their first leaves presented a band of RM -0.35 instead. Sod $=$ superoxide dismutase. 